\title{
Enablers and Difficulties for Innovation in Chile: Perceptions from Medium Size Plastic Firm Managers
}

\author{
José O. Maldifassi', Patricio Crovetto²
}

\begin{abstract}
The research objective was to understand the reasons that would impel firms to innovate. The firms analyzed in this study were medium-size firms of the plastic manufacturing sector in Chile. After the analysis of the theory related to technological innovation, a model of the drivers for technological innovation was developed. From the model a questionnaire was prepared to test which factors could influence the tendency of firms to engage in technological innovation activities. According to the data, the most influential factors that would encourage innovation in the set of firms studied are a high degree of competition in the industry, the availability of qualified workers, and a strategic relationship with customers.
\end{abstract}

Keywords: technological innovation, drivers, customers, competition, plastics, chile.

'School of Engineering and Science, Universidad Adolfo lbáñez,Avenida Padre Hurtado 750, Sausalito,Viña del Mar, Chile. email: jose.maldifassi@uai.cl

${ }^{2}$ Isapre Consalud, Santa Clara 354, Huechuraba, Santiago, Chile. email: patricio.crovetto@gmail.com

ISSN: 07 I8-2724. (http://www.jotmi.org)

Journal of Technology Management \& Innovation (C) Universidad Alberto Hurtado, Facultad de Economía y Negocios. 


\section{Introduction}

In the classical literature it has been shown that technological innovation ranks as one of the key drivers of competition across industries (Porter 1983; Burgelman and Maidique 1988 p. I, Freeman 1989 p.3, Itami and Numagami 1992). Therefore, in order for companies to maintain and improve their competitive position vis-à-vis other firms, they need to engage in a continuous process of technological innovation (Noori 1990 p. 7, Chiesa and Manzini 1998, Johnson and Scholes 2002 p. 5 I8, Daft 2009 p. 417), where improved or new products and processes are systematically introduced in their operations and markets. As many managers and engineers can testify, the inception of change in existing technologies, or even more critically, the creation of radically new technologies, is no easy task ( $M a$ et al. 20l0). There is always the risk of failure and even of bankruptcy if the effort is not managed properly. Hence, there has to exist a set of incentives and rewards that would make the effort worthwhile.

The purpose of this study was to understand what would induce medium sized firms to innovate in spite of the difficulties, costs and risks involved in the process. Medium sized firms were selected because their decision making is simpler and more straightforward than what happens in large firms, allowing for easier data collection, and their management practices are more professionalized compared to small firms, therefore findings can be considered to apply to larger firms as well.

The present article is divided as follows. In order to establish the theoretical framework, first a formal definition of technological innovation is presented. In second place, the relationship between business strategy and technological innovation is analyzed for better understanding why and how firms do incorporate the technological innovation dimension in their strategic planning process and in their competitive activities. In third place, based on the previous material, a model that relates factors that could influence the innovative capacity of firms and their actual innovative capability is developed. Following, the general results of a survey performed to a set of 19 medium sized firms 1 of the plastic manufacturing sector are described. After that the final conclusions are presented.

\section{What is Technological Innovation and what drives it?}

Technology can be defined as " $(\mathrm{t})$ he set of theories and techniques that allow for the practical benefit of scientific knowledge" (RAE, 200I). Itami and Numagami (1992) indicate that "( $\mathrm{t}$ )he purpose of technology is to produce artificial things to satisfy basic human needs." According to different definitions of the concept, it can be said that technology is the result of the combination of many elements such as information, knowledge, experience, experimentation, handcraft, and resources, both human and physical. All these are combined by means of organizational processes for the provision of products and services by firms for the betterment of society (Allen 1977), having the potential to allow individuals or organizations to do something better (i.e. operational efficiency) or to create something new (i.e. invention).

Marquis (1969) defines innovation as "the unit of technological change", and adds that "the first enterprise to make a given technical change is an innovator." Technological innovation is a process (Burgelman et al. 1988) by which technology evolves along time, first as a result of new inventions and discoveries, i.e. "technology push", and second, because of changes in the economy and in the tastes, wants and needs of the market, i.e. "market pull" (Noori 1990 p. I I, Schilling 2008 p. 23). Invention is part of the technological innovation process (Marquis 1969, Schilling 2008 p. 17), and can be considered to be motivated by an individual's drive to accomplish something new (Schilling 2008 p. 19); however, invention does not guarantee innovation (Freeman 1989 p.7, Abetti 2002). For the innovation process to take place there has to be one or more drivers that would impel individuals (Cohan 1999 p. 38) and organizations to become technological innovators. In the case of firms, the main incentives to become involved in innovative activities would be rent-seeking (Burgess 2000 p. 27I) as well as strategic (Noori 1990 p. 204).

Among the external factors that can have an influence in the innovation process carried out by firms it is possible to mention (Noori 1990 p. I I4): the prevailing economic state of affairs (i.e. growth vs. recession), market growth in the specific industry, price of specific inputs to the production process (labor, commodities, energy), and age of the specific industry (new vs. mature). In some countries there exist government policies that could stimulate or hinder the innovative effort carried out by firms (Mani 2004).

The internal factors that can influence innovation are: the innovation culture across the organization (Leavy 2005; Naranjo, Sanz and Jiménez 2010), its organizational structure (Scott 1992 p. 23 I; Schilling 2008 p. 213), its size (Noori 1990 p. II5, Robbins 1990 p. 193), the talented people they hire and foster in the organization (Leavy 2005), the amount and type of resources the organization possesses (Burgelman and Sayles 1986 p. 139), and the attitude of managers towards innovation (Börjesson and Elmquist 2008).

In order for an innovation to be successful, there has to be an adequate relationship between the innovation as such and the demands and needs of the market (Marquis 1969, Cotterman et al. 2009). The marketing function has the re- 
sponsibility of linking the market with the internal processes of the firm (Kottler 1980 p. I5), and those firms that have a better understanding and relationship with their customers are best suited to identify a potential demand or problems for their products and services, therefore they would be in a better position to innovate more successfully (Freeman 1989 p.I II, Hurley and Hult 1998, Cotterman et al. 2009). Cited by Hurley and Hult, Jaworski and Kohli (1996) suggest that "market orientation is an antecedent to innovation."

In most industries competition is nowadays a highly dynamic process where "the creation of a competitive advantage is, in principle, the result of an innovation" (Chiesa and Manzini 1998). In order for an innovation process to be effective it must be geared with the overall strategy of the organization (Roberts 200 I, Schilling 2008 p.5). The key strategic issue is innovation, therefore, technology must be considered strategically in terms of its innovation creating capabilities, where the link depends on the firm, industry and product context (Johnson and Scholes 2002 p.5/2). The need to manage technology strategically demands the close linking of internal functions (Sivadas and Dwyer 2000; Edler et al. 2002) for developing products and services that would satisfy customers' needs profitably (Kotler and Armstrong 2004 p.329). As well, because of the increasing complexity of modern technologies and systems, nowadays organizations are increasingly seeking cooperation with other firms in the same industry, with critical customers and with universities in order to reduce innovation costs and risks (Sivadas and Dwyer 2000; Chen 2008). However, not all organizations have the characteristics that would allow them to carry out successful technological innovations (Cohan 1999 p. 2). Therefore, in order to develop the organization towards innovation, managers have to craft strategies that would improve internal processes, better the technical qualifications of their employees, and establish the technical infrastructure that would allow the development and manufacturing of more sophisticated products (Baker and Sinkula 1999). All this requires capital investments (Muhammad et al. 2008) and careful planning to be effective (Calantone et al. 2003). As was already mentioned, the factors that would induce firms to engage in innovative activities can be considered to come from the environment and from within the organization. In terms of the external factors that could influence the propensity of firms to innovate it can be mentioned existing government policies and financing, and degree of rivalry in the industry. Among the internal factors the following ones can be recognized: personal characteristics of the general manager/owner of the firm, human and financial restrictions, type of product commercialized, market sought-after for the commercialization of the products, structural characteristics of the firm, and the strategic relationship with customers and suppliers that could help in the innovation process. The model derived from the reviewed literature and adopted for this study is depicted in Figure I.

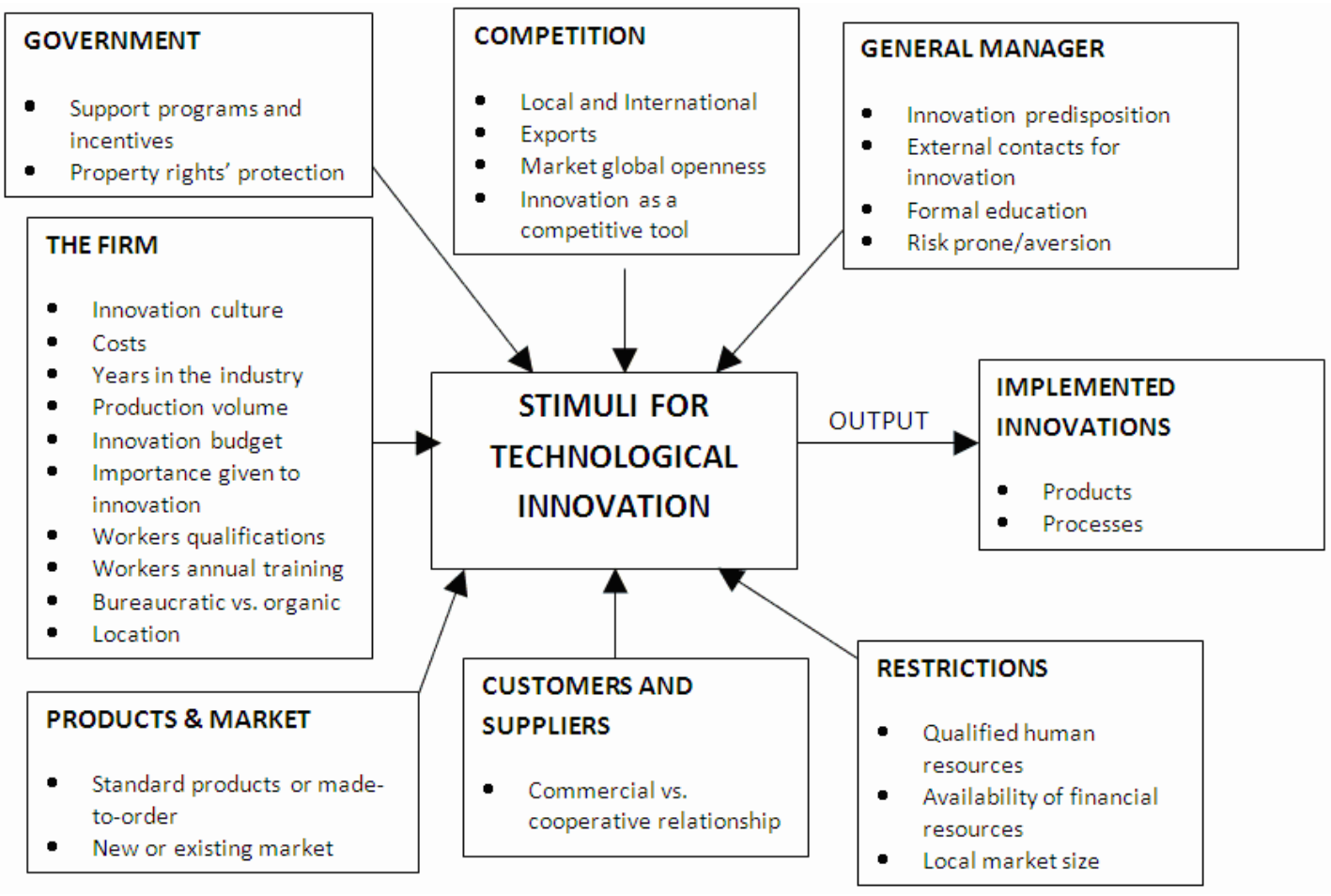

Figure I Model of the Factors Influencing the Technological Innovative Propensity of Firms

ISSN: 07I 8-2724. (http://www.jotmi.org)

Journal of Technology Management \& Innovation (C) Universidad Alberto Hurtado, Facultad de Economía y Negocios. 


\section{Methodology}

Taking into consideration the model depicted in Figure I a questionnaire was developed. This instrument was validated and improved by subjecting the operations manager of one of the firms in the industrial sector studied, as well as a professor and graduate industrial engineering students to the survey. The plastic industry was selected because it makes intensive use of technology, and in the case of Chile it exhibits high levels of competition with low margins and high raw material prices (Tumani 2008 p. 57), and because products, raw material and process machinery are normally in a constant state of change, therefore, from a strategic perspective, innovation should be very relevant.

Because in Chile the direct submission of surveys by e-mail to prospective firms exhibits very low levels of response2, a personal approach was used in this research. By direct and indirect means the general managers and operations managers of 240 medium sized plastic manufacturing firms were contacted in order to ensure their compromise to answer the survey. The firms' addresses and managers' names were obtained from the directory of the Chilean Plastic Industrial Association Organization (ASIPLA). In spite of the effort devoted, only 19 useful questionnaires were actually received, therefore the findings of this investigation can be said to be only tentative rather than conclusive. The average annual sales of the firms in the sample were approximately US\$6 million, and the average number of workers per firm was 76 .

\section{Research results}

\section{The role of the Government in Innovation}

The laws and regulations introduced by the Government play a central role in establishing an institutional environment where firms can innovate, reducing risk and creating incentives for the access to new markets and the development of innovative products and services. Accordingly, the Chilean Government has enacted several programs for helping firms to carry out innovative activities; these include, among others, partial financing of innovation projects and subsidies for firms to hire technical consultants.

In the survey interviewees were asked if they knew some of the different programs and incentives for innovation the Chilean Government had in place. Of the sample, 73.7\% knew some of the programs available. However, when the 14 managers who knew these programs were asked which they have used, only eight of them ( $41 \%$ of the sample total) had actually used any one of the programs or incentives. Thus, even though managers in general are cognizant of the existing Government programs and incentives for innovation, these are utilized by a small number of firms. The reasons can be the bureaucratic difficulties experienced by applicant firms to be granted the funds, as well as the need to regularly submit to the granting agency detailed technical and financial reports along the execution of the project. Furthermore, when asked how important the Government was as inductor of technological innovation in firms, only $37 \%$ of the interviewees answered that it was either important or very important.

One of the incentives for inducing firms to carry out technological innovations is the explicit legal possibility to discount the amount expensed in these activities in the form of income taxes. In the sample only $21 \%$ of the managers knew the existence of this instrument, clearly showing the ineffectiveness of the Government in communicating with industrialists the existence of this incentive. Regarding intellectual property rights (patents), only 16\% of the managers agreed that the policies adopted by the Chilean Government are adequate for protecting their rights, the rest of the interviewees (84\%) did not agree with the statement. Therefore, the evidence shows that managers do not perceive the Chilean Government as an effective inductor of technological innovation in firms. This finding corroborates a similar conclusion by Moguillansky et al. (2006) when analyzing innovation in Chilean wineries. In a related open ended question several interviewees answered that what should be done was "the improvement of the existing Government incentives for inducing innovation" and "to make easier the access to those programs".

Four governmental alternatives to induce firms to innovate more were proposed in the survey. The first one considered tax support for making firms more innovative, which received an average preference score of 4.3 out of a maximum of 5 ("highly agree" in a Likert scale). In the case of tax exemptions the average score was 3.95. Accelerated depreciation received and average score of 3.68 , and property rights protection an average of 3.58 , showing that all of these potential alternatives received support by the managers. Therefore, if the Chilean Government were to improve existing programs and incentives for inducing technological innovation, and improve as well the communication of such programs and incentives, Chilean firms would be more innovative. The preferred mechanism to do so chosen by the managers was the provision of direct financing, with $79 \%$ of the preferences.

\section{The role of competition}

Competitor firms in the industry play an important role in urging incumbent firms to keep abreast of the latest technologies; therefore, highly competitive industries are a munificent environment for technological innovations. In more stable and less demanding industries managers will tend to 
disregard technological innovation as a key element of their competitive strategies. In the sample, $95 \%$ of the managers agreed with the statement "Given the actual degree of competition in the industry, one way of differentiating from competitors is by means of technological innovations". As well, $84 \%$ of them support the statement "This firm sees technological innovation as a powerful competitive tool". When managers were asked if international competition did "influence or induce higher levels of technological innovation in firms", $73.7 \%$ of them agreed that it was really the case. The statement "The adoption of innovative technologies is a strategic matter for this firm" was supported by $73.7 \%$ of interviewees. Finally, regarding products' quality, $58 \%$ of managers either agreed or strongly agreed with the statement "When a product's quality doesn't allow being competitive, there is need to engage in innovative activities"; the rest of the managers were neutral and none disagreed with the statement. These results indicate that technological innovation is really stimulated by competition, and firms do consider technological innovative activities as a strategic means to deal with competitors. This finding agrees with one of the reasons found by Maldifassi (2003) for technological innovation to occur in Chilean firms.

\section{The role of managers}

As was mentioned, managers are key players in the technological innovation process because they can fully recognize the importance of this strategic issue and act accordingly, or they can hinder the technological innovative capability of the firm by restricting funds and personnel. Several personal aspects can influence the perceptions that managers have regarding technological innovation, of which it is possible to mention their attitude towards innovation and their propensity towards risk. As technological innovation entails risk, risk prone managers would tend to innovate on a more regular basis than risk-averse individuals. In $84 \%$ of the firms in the sample the general manager was the individual responsible for making decisions regarding innovation activities, in the rest of them this responsibility rested on the board of directors. Only $26 \%$ of the managers interviewed agreed that their firms had cultures that fostered technological innovation; the rest of them were either neutral or disagreed with the statement. On the other hand, 17 out of the 19 managers (89.5\%) agreed or strongly agreed that maintaining an innovation culture implied a constant effort by the firms' managers. A negative and statistically significant correlation at the 0.014 level was found between these two questions. This means that those managers that considered that maintaining an innovation culture implied a constant effort on their side $(89.5 \%)$ were the ones that did not have an innovation culture in their organizations (74\%), clearly indicating a contradiction. In the same vein, when confronted to the statement "Managers should support the rest of the members of the organization, accept their ideas, and provide incentives in relation to innovative activities", $89.5 \%$ of them either agreed or strongly agreed with the phrase. Again, this question and the one about the innovative culture of the organization exhibited a negative and statistically significant correlation at the $0,04 \mathrm{I}$ level, meaning that those interviewees who said managers should support other members in innovative activities were the ones that did not have an innovation culture. When managers were asked their agreement with the statement "This firm favors the acquisition of technology over the internal development of it", $63 \%$ of the interviewees either agreed or strongly agreed, compared to $16 \%$ who disagreed or strongly disagreed, clearly indicating the preference for acquired technology.

As can be observed, there is an evident contradiction regarding what managers say they should do to foster innovation, and the existence of an innovation culture in their firms, implying that managers are not devoting efforts to create innovation cultures in their organizations. This finding agrees with similar ones by Alvarez (1998), Maldifassi (2003) and Moguillansky et al. (2006).

The output of the innovation process in the firms was measured by asking managers to express their agreement with the following statements: "Along time, this firm has tended to introduce many products' innovations", and "Along time this firm has tended to introduce many process innovations". A five level Likert scale from strongly disagree (I) to strongly agree (5) was used. A positive statistically significant correlation at the 0.0 l level was found between these two statements, indicating that they do represent a measure of the innovative capability construct of the firm. The statements "It is convenient to have the initiative in industry with new products and services" and "It is convenient to have the initiative in industry with new processes and machinery" both received strong support by managers, with $95 \%$ of them either agreeing or strongly agreeing with the first statement and $100 \%$ with the second one. A statistically significant correlation between both statements was found, significant at the $0.0 \mathrm{I}$, therefore they can be said to adequately represent the degree of innovative riskiness construct expressed by managers. None of these last two statement correlates with the innovative output capability of the firm expressed by the products and processes innovations. Therefore, the expressed innovative capability of the firm in products and processes has no relationship with the expressed innovative riskiness according to their managers.

In order to measure the attitude towards risk of the managers, they were asked to express their agreement with the statement "There is need to take some risks in order to be successful" using the same 5-point Likert scale, receiving $95 \%$ of support in terms of agreement or strong agreement 
by the interviewees. No statistically significant correlation was found between the products' and processes' innovation questions and the attitude toward risk expressed by the managers. Again, what managers say firms should do regarding innovation and what actually the firms have done in these matters are in contradiction.

\section{The role of resources}

Firms face several difficulties when they get involved in technological innovation activities. Some of the restrictions encountered could be so severe that they could impede the implementation of these activities. Two of the most important restrictions are the availability of qualified personnel and the funds needed to support innovation.

In a first question, almost $95 \%$ of the managers agreed or strongly agreed that "the possession of qualified human resources was vital for carrying out innovative activities in the firm". In a second question, $58 \%$ of the interviewees agreed or strongly agreed that "the lack of qualified personnel had been an obstacle for carrying out innovative activities". The correlation of these two questions ended up being negative and statistically significant at the 0.006 level, indicating that qualified human resources are truly an important enabler for innovation.

Considering the annual hours devoted to training by managers, engineers, technicians and line workers in each of the firms as one of the inputs to the innovation process, and the output as the fact that each firm had carried out several products and processes' innovations, positive statistically significant correlations were found between annual hours of training by technicians with products' innovations (significant at the 0.03 level), and annual hours of training by line workers with processes' innovations (significant at the 0.002 level). In support of this, $63 \%$ of the managers agreed or strongly agreed that if firms were to invest more hours in annual training of their workers, more innovation activities could be carried out. Therefore, better trained and qualified personnel does foster innovation, corroborating previous findings by Soto (2002), Maldifassi (2003) and Moguillansky et al. (2006).

In the sample $58 \%$ of the managers agreed or strongly agreed that the lack of financial resources had been an obstacle for carrying out the innovative activities of the firm. It is worth noting that the firms in the sample are considered to be of medium size according to the Chilean classification scheme adopted by official organizations, therefore in this kind of firms it could be assumed that the available financial resources would suffice to allocate enough money to carry out technological innovation activities. Furthermore, only five out of the 19 firms in the sample $(26 \%)$ reported in the survey that they did devote some financial resources to technological innovation; one of them reporting yearly expenses of approximately US\$ 110 thousand and the second one approximately US $\$ 35$ thousand, representing in the first case $2 \%$ of annual sales and in the second case $1.6 \%$ of annual sales; the other three firms did not report in the survey the amount devoted to this purpose. These low investments are in agreement with the low investments in innovation made by Chilean wineries found by Moguillansky et al. (2006). No correlation was found between the official assignment of funds for innovation with the output of innovative activities of the firm (product and processes' innovations), probably indicating that the amount assigned to these activities is not enough to make a difference in the innovative capabilities of each firm. In conclusion, it can be said that managers do consider the lack of financial resources as a hindrance for technological innovation, as could be expected, but detailed analysis would indicate that, in this industry and for this size of firms, the lack of funds for innovation is more the outcome of a decision made by the firms' managers than a restriction imposed by the environment.

\section{The role of partners}

In the later part of the past century it was widely recognized that firms cannot operate effectively in isolation, and that those firms that do cooperate with other individuals and organizations in their environment would tend to exhibit higher levels of technological innovation. Customers and suppliers can be considered to be very important groups in the firms' environment. Thus, those firms that have cooperative agreements and frequent interaction with these two environmental players would exhibit higher levels of technological innovation than those who do not engage in these activities.

Of the managers in the sample, $68.5 \%$ of them agreed or strongly agreed that the interaction with their clients had influenced the implementation of technological innovation activities, and only $15.8 \%$ either disagreed or strongly disagreed with the statement. The opinion of the interviewees regarding the phrase "In order to have higher standards of innovative activities there is need to have a strategic cooperation relationship with my clients" received either agreement or strong agreement by $63 \%$ of the managers, with the rest of them showing a neutral attitude towards the statement and none indicating disagreement. These two questions showed to be statistically positively correlated at the 0.043 level. Fifty percent of the managers indicated that they had a cooperative and of-mutual-benefit relationship with their customers. A positive statistically significant correlation was found between this cooperative relationship with customers and the innovative capability of the firm according to implemented products' innovations (significant at the 
0.028 level) and processes' innovations (significant at the 0.042 level). Therefore, from a strategic perspective, managers consider that a cooperative relationship with customers would improve their innovative capabilities, and those firms that do have a constructive relationship with customers show that it has had a positive effect on the innovations really implemented. This strategic relationship with customers as a source of innovation coincides with the findings by Moguillansky et al. (2006).

A similar analysis as the one for clients was made for suppliers. In this case only $42 \%$ of the managers agreed or strongly agreed that the interaction with their suppliers had influenced the implementation of technological innovation activities, and $26.3 \%$ either disagreed or strongly disagreed with the statement. Again, the statement "In order to have higher standards of innovative activities there is need to have a strategic cooperation relationship with my suppliers" received either agreement or strong agreement by $58 \%$ of the managers, with the rest of them showing a neutral attitude towards the statement and none indicating disagreement. No statistically significant correlation was found between these two variables. As can be observed, the aid of suppliers as strategic inductors of innovation inside firms is lower than in the case of customers. In this case only four of the managers indicated that they had a cooperative and of mutual interest relationship with suppliers, this relationship having no correlation at all with the products' and processes' innovations implemented by the firms. Therefore, it can be said that a strategic relationship with suppliers does not help in the innovative capability of the firm.

\section{Conclusions}

Technological innovation in firms is no easy task and it demands time and effort by the organization to really occur, furthermore, it involves risks. What is needed, then, is the existence of driving factors that would entice managers to involve the firm in innovative activities.

As it was shown in this study, the Chilean Government has done a poor job as motivating agent for innovation, and if the current programs and incentives that it has established were improved, in close cooperation with industrial organizations, it would really help improve the innovative capabilities of Chilean firms.

Another finding was the fact that managers are not creating innovative cultures in their firms; therefore technological innovation is not part of the normal activities or doctrine of their workers and professionals. If managers are really convinced that technological innovation has strategic importance, they should devote time and resources to establish innovative cultures in support of their regular activities. A final point to be made regarding managers is that, according to the results of this study, risk-prone managers are not more innovative than conservative managers. This could be so because technological innovation requires much more than a proactive attitude towards new ways of acting and of betting the odds; it requires careful planning, financing, qualified personnel, attention to details, and a true customer orientation.

From a pure logical perspective, the availability of financial resources would certainly facilitate carrying out innovative activities, however, in the case of large to medium sized firms this availability should come from the strategic assignments made by managers, and it is more the outcome of the decision making process of the firms than the munificence of the firms' environment.

The results of this study show that in the case of medium-sized plastic firms in Chile, what induces innovation is the existence and recognition of competition in the local industry, the availability of qualified human resources, and a strategic relationship with customers; these three drivers for innovation coincides with findings of previous studies done in Chile. However, because of the small size of the sample, these findings should be considered as preliminary and would need to be corroborated by further studies. 


\section{References}

ABBETI, Pier A. (2002). "From science to technology to products and profits: Superconductivity at General Electric and Intermagnetics General (1960-1990)". Journal of Business Venturing. Vol. 17, 83-98.

ALLEN,T.J. (1977). Managing the Flow of Technology: Technology Transfer and the Dissemination of Technological Information within the R\&D Organization. MIT Press, Cambridge, Mass.

ALVAREZ, Rosario (1998). Adoption and use of Technology in Chilean Firms. Master Thesis, School of Industrial Engineering, Pontificia Universidad Católica de Chile, Santiago, Chile.

BAKER, William E. and James M. Sinkula (1999). "Learning Orientation, Market Orientation, and Innovation: Integrating and Extending Models of Organizational Performance". Journal of Market Focused Management,Vol. 4, 295-308.

BÖRJESSON, Sofia and Maria Elmquist (2008). "Aiming at Innovation in the Swedish Defence Industry - The Difficulties of Responding to Disruptive Market Change in a Technology Driven Context". Presented at the Organizational Learning, Knowledge and Capabilities Conference, Köpenhamn, Denmark, April 28-30. Web page http://www2.warwick. ac.uk/fac/soc/wbs/conf/olkc/archive/olkc3/papers/contribution 193.pdf. Accessed July I5, 2009.

BURGELMAN, R.A. and Sayles, L.R. (1986). Inside Corporate Innovation: Strategy, Structure, and Managerial Skills. Free Press, New York, NY.

BURGELMAN, R. A.;T.J. Kosnik and M. van der Poel (1988). "Toward an Innovative Capabilities Audit Framework", in the book Strategic Management of Technology and Innovation, Burgelman and Maidique, editors. Irwin, Homewood, Illinois, 3I-44.

BURGESS, Giles H. (2000). Industrial Organization. Prentice Hall, New Jersey.

CALANTONE, Roger, Rosanna Garcia and Cornelia Dröge (2003). "The Effects of Environmental Turbulence on New Product Development Strategy Planning". Journal of Product Innovation Management, Vol. 20, 90-103.

CHEN, Te Fu (2008). "The Creation And Operation Of Knowledge-Based Innovation Networks In High-Tech SME's". Journal of Knowledge Management Practice, Vol. 9, No. 4, 32-57.
CHIESA, Vittorio and Raffaella Manzini (1989). "Towards a Framework for Dynamic Technology Strategy". Technology Analysis and Strategic Management, Vol. I0, N I, I I I-I29.

COHAN, Peter S. (1999). Los Líderes en Tecnología. Prentice Hall, México.

COTTERMANM, Ronald, Alan Fusfeld, Pamela Henderson, Jonathan Leder, Carl Loweth, and Anthony Metoyer (2009). "Aligning Marketing and Technology to Drive Innovation". Research, Technology Management, September-October 2009, 14-20.

DAFT, Richard L. (2009). Organization Theory and Design, 10th edition. South-Western Cengage Learning, Mason, USA.

EDLER, Jakob; Frieder Meyer-Krahmer and Guido Reger (2002). "Changes in the strategic management of Technology: results of a global benchmarking study". R\&D Management,Vol. 32, 2, I49-164.

FREEMAN, Christopher. (1989) The Economics of Industrial Innovation (Second Edition). MIT Press, Cambridge, Mass.

HURLEY, Robert F. and G. Tomas M. Hult. (1998) "Innovation, Market Orientation, and Organizational Learning: An Integration and Empirical Examination". Journal of Marketing Vol. $62,42-54$.

ITAMI, Hiroyuki and Tsuyoshi Numagami. (1992) "Dynamic Interaction Between Strategy and Technology". Strategic Management Journal. Vol. 13, I19-135.

JAWORSKI, Bernard and Ajay Kohli (1996), "Market Orientation: Review, Refinement, and Roadmap". Journal of Market Focused Management, Vol. I, N², I I9-I35.

JOHNSON, Gerry and Kevan Scholes (2002). Exploring corporate Strategy:Text and Cases (sixth edition). Prentice Hall, Harlow, UK.

KOTLER, Philip and Gary Armstrong (2004). Marketing (I0a edición). Prentice Hall, Madrid.

LEAVY, Brian (2005). "A leader's guide to creating an innovation culture”. Strategy \& Leadership. Vol. 33, N 4, 38-45.

MA, Jingting; Shumei Wang and Jian Gui (2010). "A Study on the Influences of Financing on Technological Innovation in Small and Medium-Sized Enterprises". International Journal of Business and Management, Vol. 5, N², 209-2I2. 
MANI, Sunil (2004). "Government, innovation and technology policy: an international comparative analysis". Int. J. Technology and Globalisation. Vol. I, No. I, 29-44.

MARQUIS, Donald G. (1969) "The Anatomy of Successful Innovations". Innovation. Vol. I, N7, November.

MALDIFASSI, José O. (2003). "Entrepreneurship and innovation in Chilean firms: an exploratory study". International Journal of Entrepreneurship and Innovation Management, Vol. I, N I, 73-95.

MOGUILLANSKY, Graciela, Juan Carlos Salas and Gabriela Cares (2006). "Capacidad de innovación en industrias exportadoras de Chile: la industria del vino y la agroindustria hortofrutícola". Comercio Internacional $\mathrm{N}^{\circ} 79$. CEPAL, División de Comercio Internacional e Integración, Santiago, Chile, 65 p.

MUHAMMAD, Nik Maheran Nik, Muhamad Jantan and Chong Chee Keong (2008). “Technology Strategy and Firm's Revenue Growth: Empirical Evidence of Malaysian Industrial Automation Industry". International Journal of Business and Management, Vol. 3, $\mathrm{N}^{\circ}$ 7, 97-106.

NARANJO, Julia C., Raquel Sanz Valle and Daniel Jiménez Jiménez. "Organizational Culture as Determinant of Product Innovation". European Journal of Innovation Management, Vol. I 3 No.4, 20I 0, 466-480.

PORTER, Michael M. (1983). "The Technological Dimension of Competitive Strategy". Research on Technological Innovation, Management, and Policy, Vol. I, Irwin, Greenwich, Conn., I-34.

RAE (200I). Diccionario de la Real Academia Española de la Lengua. Madrid, Spain.

ROBBINS, S.P. (1990). Organizational Theory: Structure Design and Applications. (3rd edition). Prentice Hall, Indiana.

ROBERTS, Edward B. (200I). "Benchmarking Global Strategic Management of Technology”. Research Technology Management. March-April 200 I, 25-36.

SCHILLING, Melissa A. (2008). Dirección Estratégica de la Innovación Tecnológica, McGrawHill, Madrid.

SCOTT, R.W. (1992) Organizations: Rational, Natural and Open Systems. (3rd edition). Prentice Hall, Indiana.

SIVADAS, Eugene and F. Robert Dwyer (2000). "An examination of organizational factors influencing new product success in internal and Alliance-Based Processes". Journal of Marketing; Vol. 64, NI; 3I-49.
SOTO, Hector (2002). Management of Technological Innovation in National Manufacturing Firms. Undergraduate Thesis, School of Industrial Engineering, Pontificia Universidad Católica de Chile, Santiago, Chile.

TUMANI, Gabriel (2008). Proposal of a Strategic Plan for a Plastics Manufacturing Firm. Master Thesis, School of Industrial Engineering, Universidad Adolfo lbáñez,Viña del Mar, Chile.

\section{Notes}

I.- Even though this is not a very large number, it represents $7.5 \%$ of the total number of medium-size firms in the plastic manufacturing industry in Chile.

2.- In two previous non-related e-mail surveys a $2 \%$ response rate was attained. 